\title{
Using Signal Functions to Measure Third Delays in the Management of Obstetric Emergencies: A Study of Midigo Health Centre IV
}

\author{
Kizito Omona $[\mathrm{PhD}]$ \\ Lecturer, Uganda Martyrs University, Department of Health Sciences, Kampala, Uganda \\ E-mail: komona@umu.ac.ug, Tel: +256706464873 \\ DOI: 10.47760/cognizance.2021.v01i05.001
}

\begin{abstract}
:
Background: Signal functions are a representative shortlist of key interventions and activities that address major causes of morbidity or mortality and that are indicative of a certain type and level of care in a health facility. For example, signal functions indicative of "basic emergency obstetric care (EmOC)" could be provided by midwives at a lower level health centre, whereas "comprehensive EmOC" signal functions indicate a higher level of care, usually at a hospital or. Thus, signal function test is very vital in measuring Obstetric and Newborn Functionality of Health Facilities. On the other hand, third delays are the delays in receiving adequate and appropriate treatment at the healthcare facility by mothers during and after pregnancy.

Purpose: The aim of the study was to determine the quality and use of signal functions, over the past three months, in the provision of EmOC in Midigo Health Centre IV by June 2017. Secondly, it was to establish lived experiences of mothers who received EmOC services.

Materials and Methods: Purely qualitative phenomenological design was used. Sample of six mothers, six midwives and health facility in-charge were used. WHO Signal function observation tool was used to assess the functionality of the facility

Results: Midigo HC IV was categorized as NON-EmOC facility. It felt short of both WHO and Uganda national standards. This was due to policy related issues arising from failure to post medical officers and anesthetist to the facility at that time. Concerning the quality and use of signal functions; 5 out of nine signal functions (55.6\%) were performed in the past three months. For lived experiences; $66.7 \%$ of the mothers reported poor perceived quality of care and $66.7 \%$ were dissatisfied with the services they got.

Conclusion: Based on the study finding, Midigo Health Centre IV is still a Non- EmOC Health Facility, falling short of both WHO and Uganda national standards
\end{abstract}

Keywords: Signal functions, lived experiences, Emergency Obstetric Care (EmOC) 


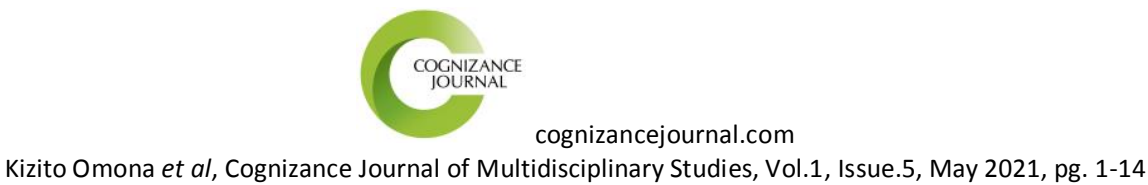

ISSN: 0976-7797

\section{INTRODUCTION}

\subsection{Background to the Study}

Signal functions are a representative shortlist of key interventions and activities that address major causes of morbidity or mortality and that are indicative of a certain type and level of care in a health facility (Gabrysch, 2012). More specifically, Emergency obstetric care (EmOC) signal functions, which is a shortlist of key life-saving obstetric interventions, have been used to assess the functionality of health facilities with respect to EmOC and to construct indicators of service provision (Gabrysch, et al., 2012). These are thought to reflect responsiveness of the health services to the main obstetric complications at basic and comprehensive level (WHO, 2009). For example, signal functions indicative of "basic emergency obstetric care (EmOC)" could be provided by midwives at a lower level health centre, whereas "comprehensive EmOC" signal functions indicate a higher level of care, usually at a hospital or . Thus, signal function test is very vital in measuring Obstetric and Newborn Functionality of Health Facilities (Omona, 2018).

Meanwhile, the three-delay model by World Health Organization (WHO) focuses on three major factors affecting the outcome of emergency preparedness during pregnancy (World Health Organization [WHO], 2015). These factors are the delays in the decision to access healthcare, delay in the identification of healthcare facility and transport to the said facility and delay in receiving adequate and appropriate treatment at the facility, respectively. It has been proved that poor patient outcome usually occurs if any of these factors contribute to undue delay in care. For instant, an inability to recognize an emergency at any level may increase the delay in the decision to seek care or give appropriate obstetric care. Likewise, the ability of the patient or a health worker to recognize an emergency is partially dependent upon the patient's or health worker's level of education among other factors (World Health Organization [WHO], 2015). These kinds of delays were emphasized in other earlier studies (Thaddeus \& Maine, 1994) and this is still similar to other reports (Uganda Bureau of Statistic [UBOS], 2015) on the subject matter.

According to other scholars, if the internal health facility delays are a major contributing factor to maternal deaths then the delays must be reduced (Bjarke, Elsass, Brigitte, Massawe, Nyakina, \& Vibeke, 2010). This reduction must be to an acceptable level before the other delays are addressed. In a project study (Borgen project, 2016), by a non-profit organization addressing poverty and hunger, it is said that in the third delay (which is delay in the provision of adequate care), postpartum hemorrhage accounts for $27 \%$ of maternal deaths whereas obstructed labor constitutes $8 \%$. The author further stressed that in developing countries, a shortage of staff, insufficient training, inadequate sanitation and antibiotic unavailability among others means health facilities are often ill-equipped to respond to a mother's needs during and after her pregnancy. These are the signal functions listed by the World Health Organization (WHO, 2009). 


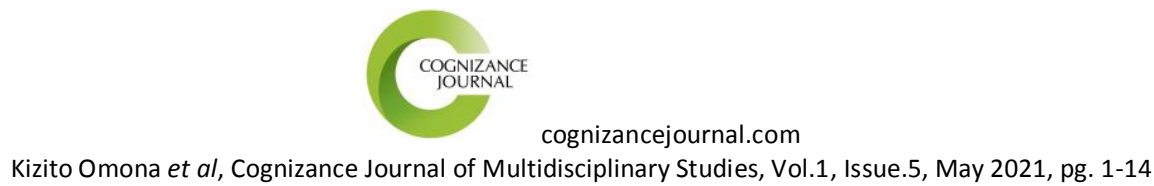

ISSN: 0976-7797

It is important to note that Goal Three, Target 3.1 of the 2015 Sustainable Development Goals seeks to "reduce the global maternal mortality rate to less than 70 per 100,000 live births by 2030" (United Nations Development Programme [UNDP], 2017). Therefore, achieving this goal may need a lot more in tackling the three delays that play a central role in the causes of maternal mortality (WHO, 2016). According to UNICEF, Maternal mortality ratio (per 100,000 live births) of Uganda was 343 in the year 2015 (United Nations Children Educational Fund [UNICEF], 2016).

In another study, it was found that $25.7 \%$ of the delays in receiving obstetric care were related to quality of medical care at the health facility (Rodolfo, José, Mary, Maria, Samira, \& Maria, 2014). This is in agreement with that of Mismay \& Morrow (Mismay \& Morrow, n.d), who studied delay and seeking of emergency obstetric care in Eritrea and found that delay due to poor quality of services at healthcare facility was at $25 \%$

The third delay is barriers to the receipt of timely and appropriate obstetric care at the facility level (Hannah, Alice, \& Stephen, 2013). In this delay, there are basically six (6) factors. These factors are grouped as; Drugs and equipment factors, Policy and guidelines factors, Human resources factors, Facility infrastructure, Patient-related and Referral-related factors, respectively. In fact, in a study on why women are dying when they reach hospital on time, it was found that the most commonly cited barriers were inadequate training/skills mix (86\%); drug procurement/logistics problems (65\%); staff shortages (60\%); lack of equipment (51\%) and low staff motivation at 44\% (Hannah, Alice, \& Stephen, 2013). In yet another study, it was found that shortages of staffs, essential equipment, medicines and blood as well as inadequate management, late or wrong diagnosis and incorrect actions were the commonest third delays in Eritrea (Mismay \& Morrow, n.d).

Emergency obstetric care at facility level is divided into two; Basic emergency care and Comprehensive emergency care services (Omona, 2018). Mothers must be assured of both services. Basic emergency obstetric care refers to lifesaving services for maternal complication being provided by a health facility or healthcare professional. It includes administration of parenteral antibiotics, oxytocin and anticonvulsants drugs for pre-eclampsia and eclampsia, manual removal of placenta and retained products and assisted vaginal delivery. In the same way, comprehensive emergency obstetric care covers all above basic care plus two other services, that is, performance of caesarean section and blood transfusion (Bhandari \& Dangal, 2014).

However, Emergency Obstetric and Neonatal Care (EmONC) intervention uses standard medical practices for the management of the seven life-threatening complications that can lead to maternal deaths. This intervention is provided through a set of services called signal functions (Gabrysch, 2012). These are; parenteral antibiotics, anticonvulsants, uterotonics, manual removal of placenta and retained products, newborn resuscitation, assisted vaginal delivery, cesarean sections and blood transfusion (Tannia, 2015). Therefore, it is important to 
note that availability and accessibility of EmONC depends on having in place four basic and one comprehensive EmONC for at least every population of 500,000 (WHO, 2015; Tania, 2015). Summary are in the table 1 below

Table 1: Signal Functions for Basic and Comprehensive EmONC

\begin{tabular}{ll}
\hline Basic EmONC Functions & Comprehensive EmONC Functions \\
\hline Parenteral Antibiotics & All Basic EmONC + \\
Parenteral Anticonvulsants & Cesarean Section \\
Parenteral Uterotonics & Blood Transfusions \\
Manual Removal of Placenta & \\
Newborn Resuscitation & \\
Removal of Retained Products & \\
Assisted Vaginal Delivery & \\
\hline
\end{tabular}

Adopted from WHO: 'Monitoring Emergency Obstetric care: A Handbook' (WHO, 2009)

In Uganda, internal delays, also known as third delay, remains a major challenge in most rural health facilities. This has dramatically affected the provision of both basic obstetric emergency care and comprehensive obstetric emergency care services. This has a huge bearing on Sustainable Development Goal (SDG) 3, target 3.1 which stresses on the reduction of the global maternal mortality ratio to less than 70 per 100,000 live births by 2030 (UNDP, 2017). Maternal mortality ratio (per 100,000 live births) of Uganda was 343 in the year 2015 (UNICEF , 2016). Therefore, if Uganda is to contribute to this global development agenda, then a lot still has to be done to bridge these delays.

\subsection{The study Area}

The study was in Midigo Health Centre IV which is a government health facility, located in Yumbe district (West Nile), in particularly located in Midigo Sub County. The total bed capacity of Midigo Health Centre IV is 73beds (Ministry of Health $[\mathrm{MoH}]$, 2015). The sub county in which the health facility is located, Midigo Sub County, has a total population of 37,100people which is $7.64 \%$ of the total population of Yumbe district of 485,582 persons (Uganda Bureau of Statistic [UBOS], 2015).

\subsection{Conceptual Framework}

There complex and interlinked issues around maternal death. They are complex to comprehend, as poor maternal outcomes are influenced by many different categories of events or conditions (McCarthy, 1997, as cited in Tannia (2015)). Whereas the three delays model tackles all the delay cycle, this model is customized only for the third delay. It addresses the many levels of determinants, both from the demand and supply sides. The basic premise of this customized model is that there is the third delay phase that prevents a mother from receiving appropriate obstetric emergency care. Remember that this is at health facility level (Uganda Bureau of Statistic [UBOS], 2015). On the 
demand side barriers, better perceived quality of care and benefits, minimal formal/ informal payments as well as good socioeconomic and educational status of mothers tend positively influence mothers to come to the health facility for services. Similarly, improving the supply side improves maternal outcomes (Thaddeus \& Maine, 1994).

Demand-Side \& Supply-Side Barriers to Accessing Care \& Third Phase of Delay

\section{Demand side Barriers}

Perceived quality of

care \& Benefit

\& informal

payments

Socioeconomic \&

educational status

of women
Supply side Barriers

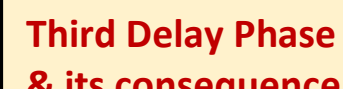

$\&$ its consequence

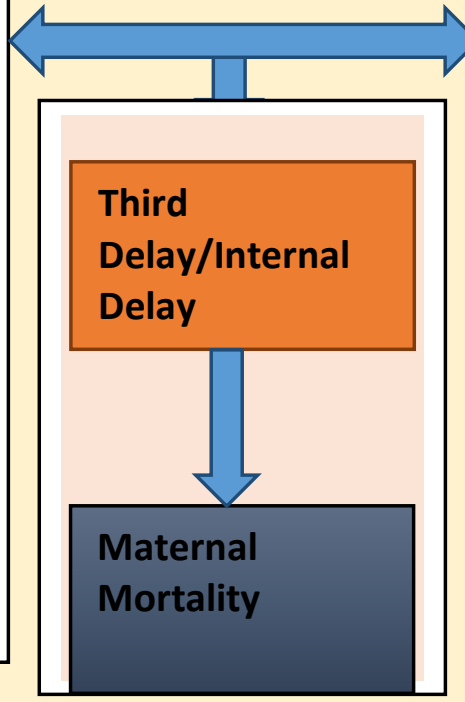

Wage, availability \&

quality of $\mathrm{H} /$ workers

Quality of care \&

Cleanliness of the facility

Availability \& quality of medicines, supplies, referral system

Location \& Hours of

operation

\section{Figure 1: Demand-Side \& Supply-Side Barriers to Accessing Obstetric Emergency Care \& Third Phase of Delay: Adopted from Thaddeus and Maine (Thaddeus \& Maine, 1994)}

The intervals between critical events and actual receiving of definitive Emergency Obstetric Care (EmOC) by a mother, is what constitutes internal delays (Third Delays). See figure 2. A strategy in reducing the time spent between these intervals of events is the way to go if improvement is to be made. 


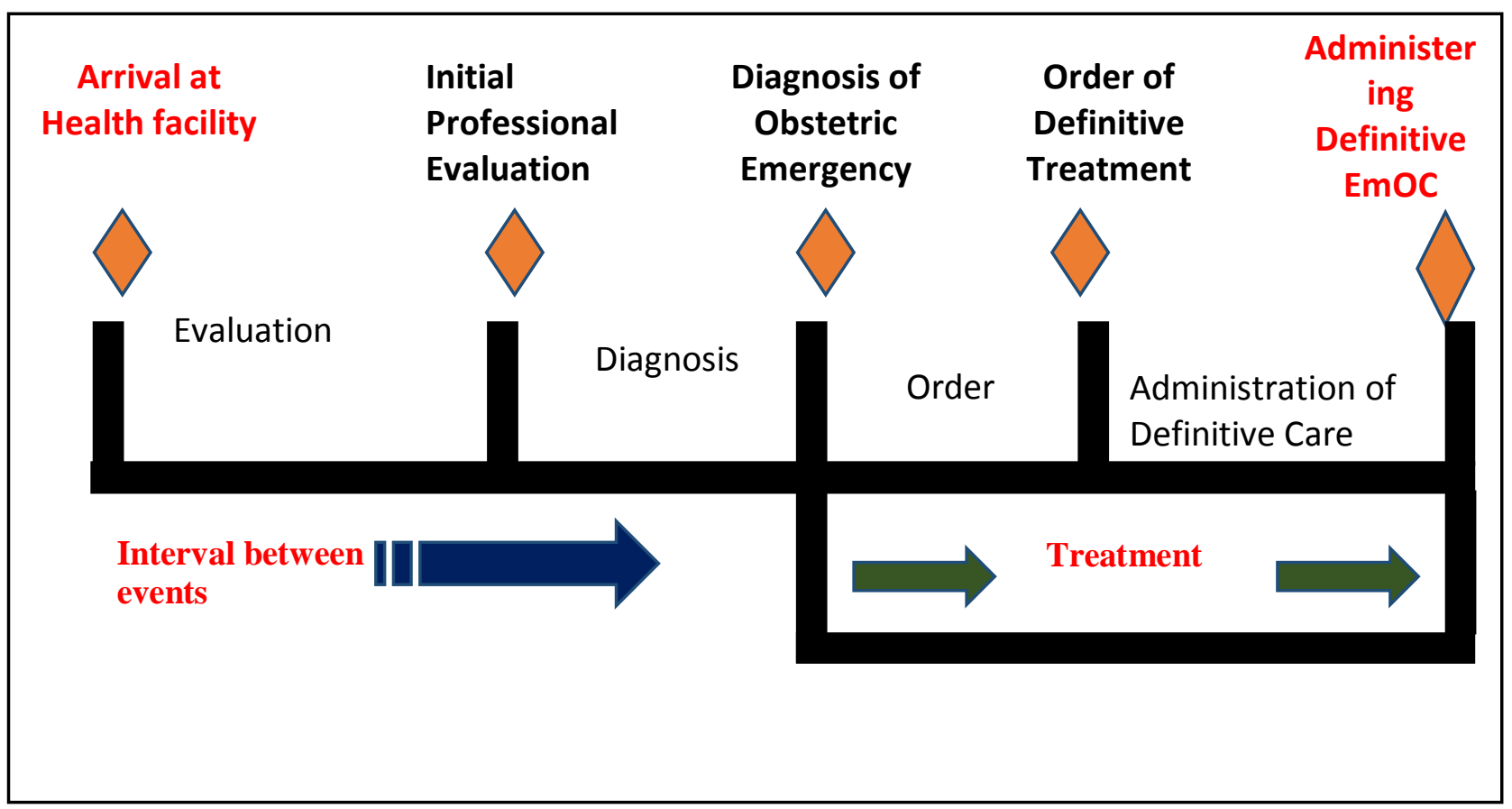

Figure 2: Intervals between Critical Events \& Actual Receiving of Definitive EmOC by mothers

\subsection{Specific Objectives of the study}

The study had two specific objectives. These are;

I. To determine the quality and use of signal functions, over the last three (3) months, in the provision of Emergency Obstetric and Newborn Care in Midigo Health Centre IV by June, 2017

II. To establish the lived experiences of mothers who received obstetric emergency care services in Midigo Health Centre IV by June, 2017

\section{MATERIALS AND METHODS}

\subsection{Study Design}

The study employed a purely qualitative descriptive phenomenological design. This design gave all the detailed information needed for the study.

\subsection{Study Population}

The study population was the healthcare professionals, particularly midwives, of Midigo Health Centre IV and mothers who got emergency obstetric services from the health facility within the month of June, 2017.

\subsection{Sample size estimation}

The researcher intended and had all the six (6) midwives available in the facility as healthcare professional respondents. One of the six midwives, the most senior with at least 5years experience, served as a key informant. The health facility in-charge was another key informant, making a total of two (2) key informants. Similarly, there were six (6) randomly selected respondent mothers who have ever had, at least three (3) emergency obstetric care services from the health facility. So, the total number of respondents for the study was fourteen (14). 


\subsection{Sampling Procedure}

A purposeful sampling technique was employed for the midwives. The mothers were randomly selected using the register for the month of June, 2017. A home visit was made for the 6 selected mothers to capture data on a variety of obstetric emergency care services received.

\subsection{Signal Functions as Study Variables Used}

The study variables were summarized in table 2 below;

Table 2: Variables and indicators for use of Basic and Comprehensive signal functions

\begin{tabular}{ll}
\hline $\begin{array}{l}\text { Dependent Variables for Use of Basic and } \\
\text { Comprehensive Signal Functions }\end{array}$ & Indicators \\
\hline Parenteral Antibiotics & Medicine order records, Dispensing logs \\
\hline Parenteral Anticonvulsants & Medicine order records, Dispensing logs \\
Parenteral Uterotonics & Medicine order records, Dispensing logs \\
Manual removal of placenta & Procedure records \\
Newborn Resuscitation & Procedure records \\
Removal of Retained Products & Procedure records \\
Assisted Vaginal Delivery & Procedure records \\
Cesarean Section & Procedure records \\
Blood Transfusions & Records \\
\hline
\end{tabular}

From the list of dependent variables in table 2 above, responses were elicited; backed by explanations as shown in table 3 below;

Table 3: Tool Used for Variables and Responses Elicited

\begin{tabular}{|c|c|c|}
\hline Variables & Performed in past 3 months? & $\begin{array}{l}\text { If not performed in past } 3 \text { months, } \\
\text { why? }\end{array}$ \\
\hline \multirow{3}{*}{$\begin{array}{l}\text { (a) Administer } \\
\text { antibiotics }\end{array}$} & 0. Yes & 1. Training issues \\
\hline & 1. No & $\begin{array}{l}\text { 2. Supplies, equipment, } \\
\text { drugs issue } \\
\text { 3. Management issue }\end{array}$ \\
\hline & & $\begin{array}{l}\text { 4. Policy issues } \\
5 \text {. No indication }\end{array}$ \\
\hline \multirow{5}{*}{$\begin{array}{l}\text { (b) Administer uterotonic medicine } \\
\text { (i.e. parenteral oxytocin) }\end{array}$} & 0. Yes & 1. Training issues \\
\hline & 1. No & $\begin{array}{l}\text { 2. Supplies, equipment, } \\
\text { drugs issue }\end{array}$ \\
\hline & & 3. Management issue \\
\hline & & 4. Policy issues \\
\hline & & 5. No indication \\
\hline
\end{tabular}




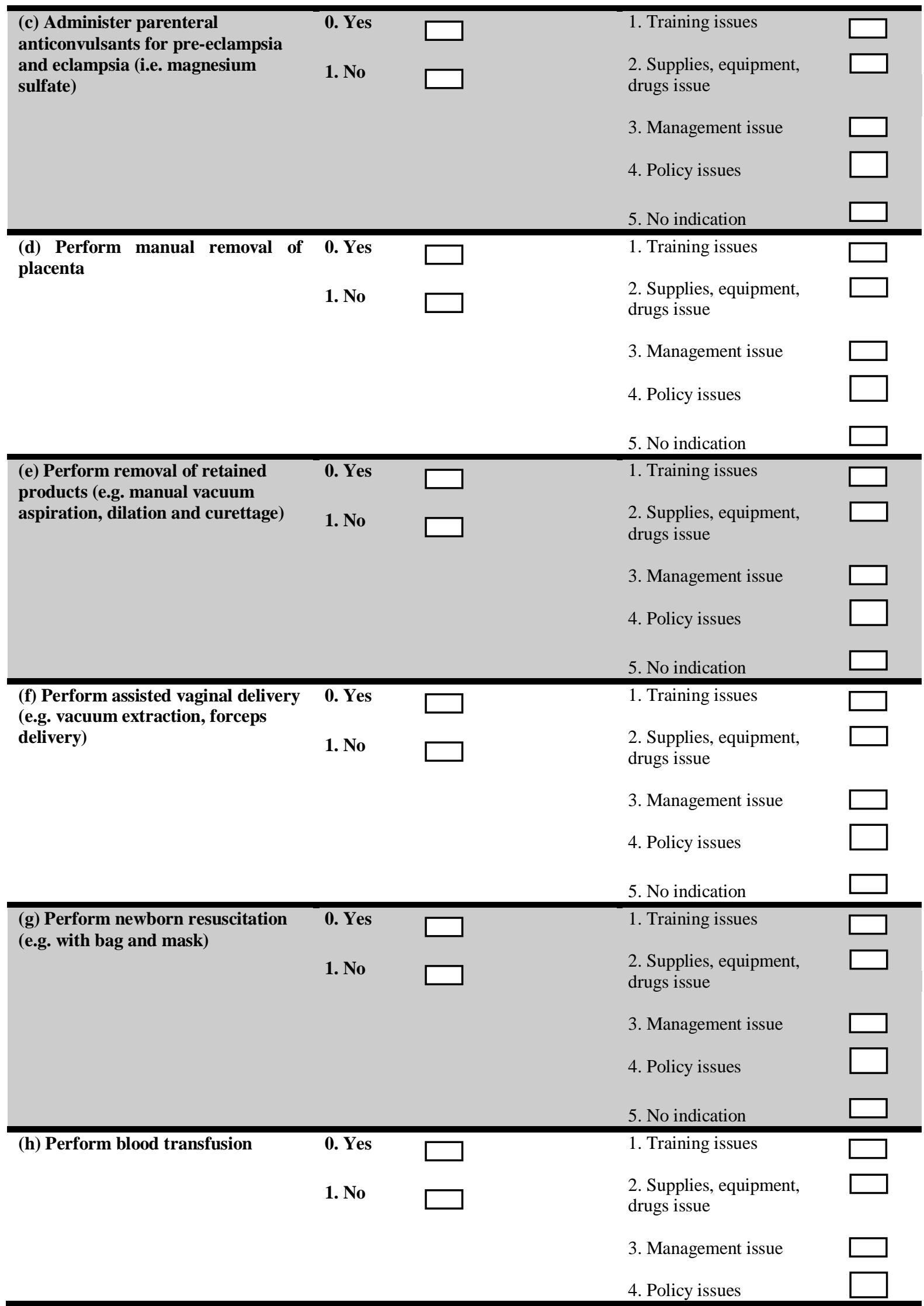




\begin{tabular}{lll}
\hline $\begin{array}{l}\text { (i) Perform surgery (e.g. caesarean } \\
\text { section) }\end{array}$ & $\mathbf{0 . Y e s}$ & 5. No indication \\
& $\mathbf{1 . N o}$ & $\begin{array}{l}\text { 1. Training issues } \\
\text { drugs issue }\end{array}$ \\
3. Management issue & 4. Policy issues \\
5. No indication
\end{tabular}

Note: For the determination of EmOC Status of the health facility, WHO guideline was used. Refer to the table 4 below. Check only one category below.

Table 4: Key for Categorization of EmOC Status of the Health Facility

\begin{tabular}{ll}
\hline Responses Obtained (From table 4) & EmOC Status Catagorization \\
\hline If allquestions $\mathrm{a}-\mathrm{i}=$ Yes, tick & $\begin{array}{l}\text { Categorize as Comprehensive EmOC } \\
\text { Facility }\end{array}$ \\
If all questions $\mathrm{a}-\mathrm{g}=$ Yes, tick & Categorize as Basic EmOC Facility \\
If any questions $\mathrm{a}-\mathrm{g}=\mathrm{No}$, tick & Categorize as Non-EmOC Facility \\
\hline
\end{tabular}

Adopted from: WHO (2009); Monitoring Emergency Obstetric Care: A Handbook

\subsection{Data Collection Procedures}

The required data was collected by observation using prepared observation guide. The guide had all the observable data needed (See table 3 for details of the tool). Semi-structured interview guide was also used and prepared in two languages; both English and Aringa, the local language. Similar interview guide was also used for the mothers. The researcher conducted face-to-face in-depth interviews using the designated guides for each respondent healthcare professional and mothers.

\subsection{Data Management, Analysis and Presentation Methods}

Data was tallied manually and simple computation done. Other qualitative data was analyzed verbatim, transcribed, coded and content analysis done. Transcription of the interviews was analyzed using descriptive non-thematic approach.

\subsection{Ethical Requirements}

Ethical requirements in research was well adhered to, as necessary 


\section{RESULTS}

\subsection{Background Characteristics of Respondents}

There were 6 midwives in the facility; one participated as a key informant. Results of the key informant interview were approved by the other five midwives and the health facility In-charge, in what is described as member checks. Out of the 6 respondent mothers, two had received Emergency Obstetric Care (EmOC) three times from Midigo Health Centre IV and the rest of them received EmOC more than 5times. Two mothers had ever been referred out while the rest were not. Again, three out of 6mothers had good maternal outcomes and another three had bad outcomes.

\subsection{Midigo Health Facility Categorization by Signal Functions Performed}

The key informants were asked about a list of dependent variables, signal functions performed in the past three (3) months, to ascertain their practice in Midigo HC IV. The responses were as follows;

Table 5: Responses Elicited for Categorization of the Facility

\begin{tabular}{|c|c|c|c|}
\hline \multirow[t]{2}{*}{ S.No } & \multirow[t]{2}{*}{ Dependent Variables } & \multicolumn{2}{|c|}{ Responses } \\
\hline & & $\begin{array}{l}\text { YES, signal } \\
\text { function done }\end{array}$ & $\begin{array}{l}\text { NO, signal function } \\
\text { not done }\end{array}$ \\
\hline 1 & Administer parenteral antibiotics & $\checkmark$ & \\
\hline 2 & $\begin{array}{l}\text { Administer uterotonic medicine (i.e. } \\
\text { parenteral oxytocin) }\end{array}$ & J & \\
\hline 3 & $\begin{array}{l}\text { Administer parenteral anticonvulsants for } \\
\text { pre-eclampsia and eclampsia (i.e. } \\
\text { magnesium sulfate) }\end{array}$ & $\checkmark$ & \\
\hline 4 & Perform manual removal of placenta & & $\mathbf{X}$ \\
\hline 5 & $\begin{array}{l}\text { Perform removal of retainedproducts (e.g. } \\
\text { manual vacuum aspiration, dilation and } \\
\text { curettage) }\end{array}$ & & $\mathbf{X}$ \\
\hline 6 & $\begin{array}{l}\text { Perform assisted vaginal delivery (e.g. } \\
\text { vacuum extraction, forceps delivery) }\end{array}$ & & $\mathbf{X}$ \\
\hline 7 & $\begin{array}{l}\text { Perform newborn resuscitation (e.g. with } \\
\text { bag and mask) }\end{array}$ & 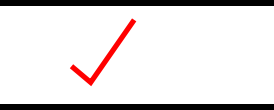 & \\
\hline 8 & Perform blood transfusion & $\checkmark$ & \\
\hline 9 & Perform surgery (e.g. caesarean section) & & $\mathbf{X}$ \\
\hline
\end{tabular}

$\checkmark \quad=$ Signal function performed in past three months, $X=$ Signal function not done

Therefore, from table 5 above, Midigo Health Centre IV performed five out of the nine signal functions for the past three months before the study. Based on WHO standard, the facility was then categorized as a NON- EmOC Health facility (See table 4 on key for categorization). All the four 


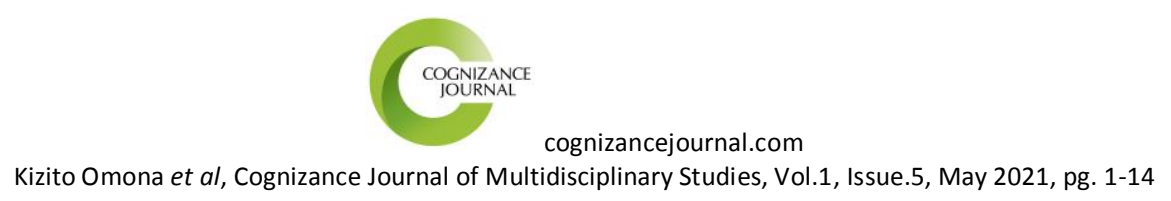

ISSN: 0976-7797

signal functions not performed in the said period were meant to be performed by a medical officer, who was not fully stationed in the health facility.

\subsection{Lived Experiences of Respondent Mothers}

When the mothers were asked to share their lived experiences after getting EmOC from Midigo HC IV, four out of 6 mothers $(66.7 \%)$ reported poor perceived quality of care at the facility. For example, mother A reported as;

"[...] The quality of care was too bad because I was referred out on a Boda-Boda motor cycle and yet an Ambulance was available. Even if there was no fuel, I would accept to meet the cost but this option was not given to me. The midwives were a bit in a rash to send me away."- Mother A

On the same subject matter, Mother E reported as below;

"[...] I cannot rate the quality of care but next time I better make money and go to a referral hospital direct. I don't want to waste a lot of time because my baby would die as a result those delays in the facility. Anyway, I know they are now trying to improve the system"- Mother $\mathbf{E}$

However, one mother who had good maternal outcome had this to say;

"I delivered all my five children from there and they are all okay. I think I will continue to go to Midigo HC IV even if certain things are not good enough [...]"

The respondent mothers were also asked whether the services they got met their expectation. Four out of six reported that their expectations were met. The two mothers whose expectations were not met were referred out and both had poor maternal outcomes. For example, mother $\mathrm{C}$ reported as follows;

"[...] My expectations were not met at all. I reached Midigo early but they delayed me and yet they knew the doctor was not around. After long hours in the facility, I was told to hire a motorcycle and go to Yumbe hospital. From Yumbe hospital, I took sometimes with the health workers who eventually referred me to Arua Referral Hospital. By the time I was to be operated from Arua Referral Hospital, my baby was already dead. Even me, I nearly died. So, my expectations were not met at all [...]”Mother C

When the mothers were asked about their satisfaction with services offered to them, four out of six were dissatisfied. One of the satisfied mothers reported as follows;

"[...] For me, things have always been better because God has always been with me.

God has always helped me to deliver faster and with minimal assistant from midwives", Said Mother F 


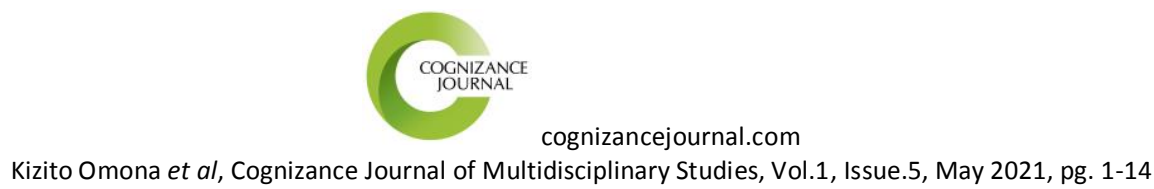

ISSN: 0976-7797

However, one of the dissatisfied mothers had this to say;

"[...] I think it would be better if these health workers go deep to the community to tell us motherly about the services that they don't have. This would help us to prepare early enough to go far away for delivery. Me and my husband are poor people and so when we are told at short notice, we cannot afford referral. This is why I lost my baby", reports mother D

\section{DISCUSSION}

\subsection{Discussion of Results}

As per the study, Midigo Health Centre IV was found to be a Non- EmOC Health Facility. The national standard requires that all health centre IVs in Uganda must be able to provide both Basic and Comprehensive Emergency obstetric care services. This finding is different from a similar study but bigger health facility in the same region, Arua Regional Referral Hospital (ARRH) where ARRH was found to be an EmOC Health Facility using the same tool (Omona, 2018). The predominant reason for this fall was district policy issues related to failure to post the required critical staffs to the health facility. Emergency obstetric care (EmOC) signal functions, which is a shortlist of key life-saving obstetric interventions, have been used to assess the functionality of health facilities with respect to EmOC and to construct indicators of service provision (Gabrysch, et al., 2012). These are thought to reflect responsiveness of the health services to the main obstetric complications at basic and comprehensive level (WHO, 2009).

\subsection{Discussion of Meaning and Importance of Findings for Ugandan Health System}

From findings in table 5, four (4) signal functions were not performed in the past three months. These were; (1) manual removal of placenta, (2) removal of retained products (example; manual vacuum aspiration, dilation and curettage), (3) assisted vaginal delivery (example; vacuum extraction, forceps delivery) and (4)caesarean section. These functions were supposed to be done by a medical officer, who due to policy gap was not available on station at the time.

This means that the absence of a single cater in a team markedly affects the performance of signal function, hence altering the EmOC status of a health facility. This contributed significantly to third delay in receiving care in Midigo HC IV.

The fact that two out of six mothers reported that their expectations were not met and four (4) mothers were dissatisfied with services meant the third delay was significantly felt by the users. Therefore, meeting mothers' satisfaction increases health facility delivery.

\section{CONCLUSION}

Based on this study finding, Midigo Health Centre IV is still a Non- EmOC Health Facility, falling short of both World Health Organization and Uganda national standards 


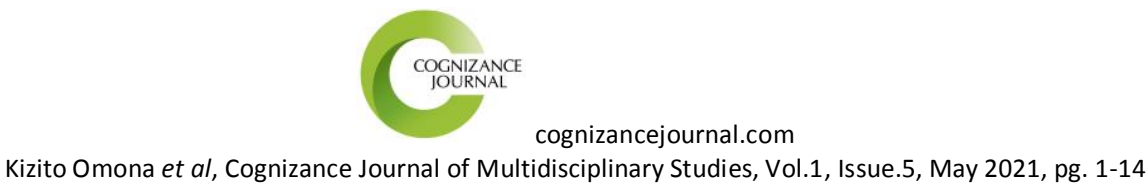

ISSN: 0976-7797

\section{RECOMMENDATION}

The investigator strongly recommends the district authority to deploy critical staffs to Midigo HC IV in order to resume its functional status.

\section{DECLARATIONS}

The author declares no competing interests, what-so-ever

\section{ACKNOWLEDGEMENTS}

The author would like to thank the management of Midigo Health Centre IV and the office of District Health Officer (DHO) _ Yumbe District Local Government, for their corporation and tireless contribution towards supporting research as measure to inform service delivery

\section{REFERENCES}

1) Bhandari, T. R., \& Dangal, G. (2014). Emergency Obstetric Care: Strategy for Reducing Maternal Mortality in Developing Countries. NJOG, 9 (17), 8-16. Available at: njog.org.np/njog/index.php/njog/article/download/71/43/.

2) Bjarke, L. S., Elsass, P., Brigitte, B. N., Massawe, S., Nyakina, J., \& Vibeke, R. (2010). Substandard emergency obstetric care - a confidential enquiry into maternal deaths at a regional hospital in Tanzania. Tropical Medicine and International Health, 18 (8), 894-900. DOI:10.1111/j.1365-3156.2010.02554.x.

3) Borgen project. (2016). The "Three Delays" at the Root of Maternal Mortality [Blog Post]. Retrieved from https://borgenproject.org/the-three-delays-maternal-mortality/

4) Gabrysch, S. (2012). Signal functions for obstetric and newborn care, we need your opinion![Blog Post]. Retrieved May 4th, 2021, from Healthy Newborn Network: https://www.healthynewbornnetwork.org/blog/signal-functions-for-obstetric-andnewborn-care-we-need-your-opinion/

5) Gabrysch, S., Civitelli, G., Edmond, K. M., Mathai, M., Ali, M., Bhutta, Z. A., et al. (2012). New Signal Functions to Measure the Ability of Health Facilities to Provide Routine and Emergency Newborn Care. Plos Medicine, 9 (11), DOI: https://doi.org/10.1371/journal.pmed.1001340.

6) Hannah, E. K., Alice, S., \& Stephen, H. K. (2013). Why Are Women Dying When They Reach Hospital on Time? A Systematic Review of the 'Third Delay'. Plos One, 8 (5), DOI: https://doi.org/10.1371/journal.pone.0063846.

7) Ministry of Health [MoH]. (2015). Annual Health Sector Performance Report: Financial Year 2014/2015. Kampala: Author.

8) Mismay, G., \& Morrow, R. H. (n.d). Delay in Seeking and Receiving Emergency Obstetric Care in Eritrea. Journal of Eritrean Medical Association (JEMA), Available at https://www.ajol.info/index.php/jema/article/viewFile/52700/41303.

9) Omona, K. (2018). Third Delays in the Management of Obstetric Emergencies: A Qualitative Study of Arua Regional Referral Hospital - Uganda. Texila International Journal of Medicine , 6 (1), DOI: 10.21522/TIJMD.2013.06.01.Art001. .

10) Rodolfo, C. P., José, G. C., Mary, A. P., Maria, H. S., Samira, M. H., \& Maria, L. C. (2014). Delays in receiving obstetric care and poor maternal outcomes: results from a 
national multicentre cross-sectional study. BMC Pregnancy and Childbirth , 14 (159), DOI: 10.1186/1471-2393-14-159.

11) Tannia, T. (2015). Signal Functions for Emergency Obstetric Care (EmONC) as an Intervention for Reducing Maternal Mortality: A Survey of Public and Private Health Facilities in Lusaka District, Zambia. Master's Dissertation, University of Zambia.

12) Thaddeus, S., \& Maine, D. (1994). Too Far to Walk: Maternal Mortality in Context. Social Science and Medicine , 38 (8), 1091-1110. DOI: 10.1016/02779536(94)90226-7.

13) Uganda Bureau of Statistic [UBOS]. (2015). National Population and Housing Census 2014. Kampala: Author.

14) Uganda Bureau of Statistic [UBOS]. (2015). National Population and Housing Census 2014. Kampala: Author.

15) United Nations Children Educational Fund [UNICEF] . (2016). Maternal and Newborn Health Disparities_Uganda [Pdf online] . Retrieved from UNICEF.org.

16) United Nations Development Programme [UNDP]. (2017). Sustainable Development Goal, Goal 3 targets [Blog Post]. Retrieved from http://www.undp.org/content/undp/en/home/sustainable-development-goals/goal-3good-health-and-well-being/targets/

17) WHO. (2009). Monitoring Emergency Obstetric Care: a Handbook [e-book]. Geneva: Author.

18) WHO. (2016). World Health Statistics Data Visualizations Dashboard [Blog Post]. Retrieved from http://apps.who.int/gho/data/node.sdg.3-1?lang=en

19) World Health Organization [WHO]. (2015). Applying the lessons of maternal mortality reduction to global emergency health. Bulletin of the World Health Organization , 93, 417 - 423. DOI: http://dx.doi.org/10.2471/BLT.14.146571. 